\title{
VISUALIZATION ON FOSSIL-FUEL CARBON DIOXIDE (CO2) EMISSIONS FROM BUILDINGS IN TOKYO METROPOLIS
}

\author{
R. Cong ${ }^{1 *}$, M. Saito ${ }^{1}$, R. Hirata ${ }^{1}$, A. Ito ${ }^{1}$, S. Maksyutov ${ }^{1}$ \\ ${ }^{1}$ National Institute for Environmental Studies, Center for Global Environmental Research, 305-8506 Tsukuba, Japan \\ richao.cong@nies.go.jp *
}

Commission IV, ICWG III/IVb and WG IV/4

KEY WORDS: Fossil fuel $\mathrm{CO}_{2}$ emissions, High resolution map, Population census, Urban building emissions, GIS, 3D map

\begin{abstract}
:
In this paper, we developed a method on quantifying carbon dioxide $\left(\mathrm{CO}_{2}\right)$ emissions from each building of Tokyo. And the method basing on bottom-up approach and supplemented with some downscaling efforts that could be applied in any other city of Japan. The high-resolution emission map is achieved by linking the national census data with spatial data. At first, the emissions from fossil fuel consumption (nonelectric) in residential and industrial \& commercial buildings are counted by the census area level and then allocated to each building by using the height, site area, floor and type of buildings. The types of buildings are distinguished by using the information on building type contained in urban landscape raster map. The emissions are estimated and mapped by Geographic Information System (GIS) technique. The total $\mathrm{CO}_{2}$ emissions from residential buildings of Tokyo in 2014 are about $5,826 \mathrm{Gg}$ and that from industrial \& commercial buildings are about 13,085 Gg. This method will be helpful for high resolution quantification of $\mathrm{CO}_{2}$ emissions in local scale.
\end{abstract}

\section{INTRODUCTION}

The rise of atmospheric carbon dioxide $\left(\mathrm{CO}_{2}\right)$ concentration due to anthropogenic emissions is the largest contributor to modern climate change. A system containing monitor, report and validation (MRV) processes is made for better understanding of it. To make actions for greenhouse gas (GHG) emissions mitigation, the GHG inventory is compiled as a major measure to quantitative them. National GHG emissions inventories (EI) document a nation's GHG sources and sinks over the course of a year that could track the changes of anthropogenic emissions. As the global urban population now exceeding 50 percent, the role of cities is recognized as a major driver of global GHG emissions (Satterthwaite, 2008). Moreover, the global carbon project pointed out that the detailed spatial distribution information on the sources of emissions is urgently needed for policy making on mitigation of climate change. The quantitative GHG emissions for the urban area has become more and more important.

In recent year, research on using the atmospheric $\mathrm{CO}_{2}$ observation data by satellite to quantitative the anthropogenic source emission has been conducted (Duren and Miller, 2012). To make the inversion analysis on urban domain, the highresolution emissions inventory is essential. However, that kind of inventories or previous literatures are rare. Fine-grained EI are made such as Hestia project (Gurney et al., 2012). Hesita project has provided a method to quantify the on-site fossil fuel $\mathrm{CO}_{2}$ emissions down to the individual buildings, road segments and industrial/electricity production facilities in Indianapolis. However, the development of fine scale EI is often prevented by the available and reliable data. After the case of Indianapolis, familiar efforts on the EI at the building-level resolution have been made: Sassari (Sanna et al., 2014), Los Angeles (Feng et al., 2016), Salt Lake City (Patarasuk et al., 2016). Therefore, a method could be widely applied is essential.

In Japan, there has been no reviewed paper or public site on high resolution GHG EI like Hesita project compiled at urban/sub-national level yet. A national inventory called East Asian Air Pollutant Emission Grid Database for Japan (EAGridJapan) is made from downscaling the national total emissions to a $1 \times 1 \mathrm{~km}$ mesh by using relevant spatial data (Kannari et al., 2007). The latest version of it is EAGrid-Japan2010 (Fukui et al., 2014). However, downscaling national emissions data with population or nightlights data faces the challenge that these two kinds of maps are not proportional to either population or nightlights at a sufficiently fine scale. For instance, some bright areas with few people, and some dark areas with many people; coal-fired power plants are not exactly coincident with where people live or lights are on (Rayner et al., 2010). As described in (Mori et al., 2015), he made efforts to compile an inventory for Osaka from major emitter sources by bottom-up and some downscaling approaches. The resolution of it reached around $0.5 \times 0.5 \mathrm{~km}$.

Since the Greenhouse gases Observing SATellite (GOSAT) is launched by Japan in 2009, using satellite observation result to clarify the global carbon cycle has been considered with more credibility. For wide inversion analysis in local scale, much more high resolution urban/sub-national EI datasets are needed. To fix these challenges, we try to develop a fine-grained EI in Japan at sub-national level and the method could be applied in any other cities of Japan. In this paper, efforts are made to estimate $\mathrm{CO}_{2}$ emissions from the fossil fuel consumed in all

\footnotetext{
* Corresponding author
} 
buildings of Tokyo by building level through Geographic Information System (GIS) technique.

Different with the approach that using energy consumption simulation tools in Hestia project (Zhou et al., 2010), in this paper, residential emissions are previously estimated basing on population census and industrial \& commercial emissions are estimated basing on the economic census data. The relevant annual nonelectric carbon intensity data are derived from an investigation report on energy consumption of residential sector and energy balance table of Tokyo for industrial \& commercial sector. Then they are allocated into each building by total floor area. The approach and results described in this paper reflect the territorial-based fossil fuel $\mathrm{CO}_{2}$ emissions from buildings as opposed to consumption-based, excluding upstream or lifecycle associated emissions. That associated with electricity consumption in buildings are quantified at power plant sector and, hence, not included in this paper. Subsequently, we describe the study area and the methods by which we estimate the emissions at census area level from residential and industrial $\&$ commercial buildings, and allocate them into each building. We then discuss the result and future steps.

\section{METHODOLOGY}

2.1 Study area and framework for building emissions estimation by building level

Tokyo metropolis is the capital of Japan with a large population of 13,617,444 in 2016 and area of $2,188 \mathrm{~km}^{2}$. To conduct the pilot study, Tokyo is chosen as study area. In this study, $\mathrm{CO}_{2}$ emissions are estimated as the resolution processing by ArcGIS v. 10.4. During the whole resolution process, the coordination system of WGS 1984 is used in each map. $\mathrm{CO}_{2}$ emissions are estimated by the activity data multiplied by the emissions factors. As shown in figure 1, the whole workflow contains three steps: data preparation, emissions estimation from census data, and emissions allocation for each building.

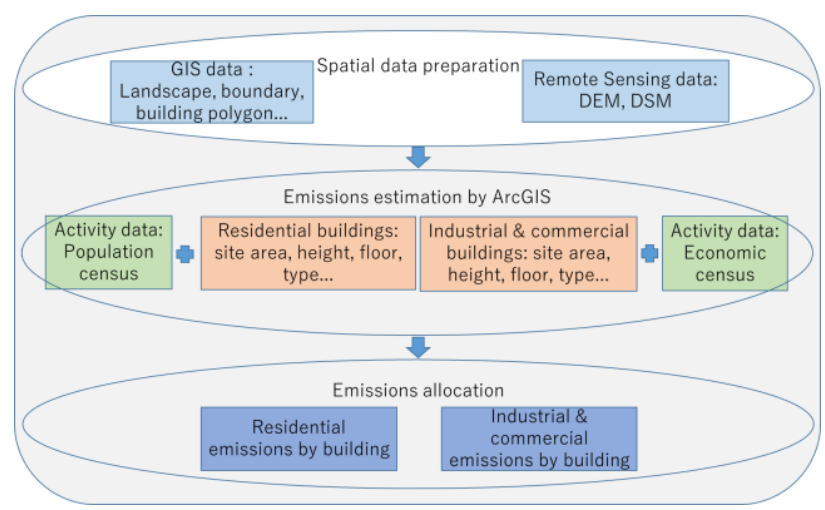

Figure 1. Conceptual framework of building emissions mapping

\subsection{Add attributes for all buildings}

As our next step is to allocate the emissions at census level to all buildings, the essential attributes of height, site area, floor, total area, and type of buildings should be added for each building. To achieve that, digital elevation model (DEM), digital surface model (DSM), boundary map, and the urban landscape raster map are used for height calculation and building types distinction. Data processing on how to add attributes for buildings is described in figure 2. Building types are firstly distinguished, the site area, height, floor number and the total floor area of buildings (in purple) are then added by GIS tools and the names of that are written in red.

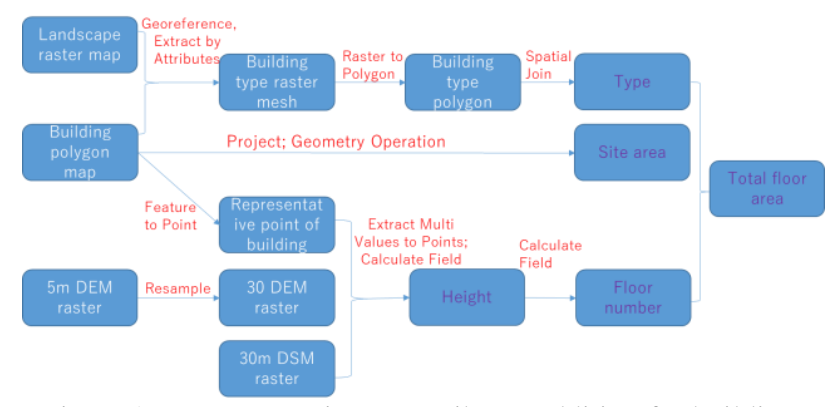

Figure 2. Data processing on attributes addition for buildings

After the attributes addition for each building, spatial extraction and spatial join tools are used to distinguish all buildings into 3 categories: detached building, collective building, industrial \& commercial building. Residential buildings are firstly distinguished as two types using the landscape map at a resolution of $4 \times 4 \mathrm{~m}$ and boundary map. The rest buildings are regarded as industrial \& commercial use. For that, Supervised Classification tool is applied. As shown in figure 3, residential buildings land use map distributed as two types. The total numbers of each type of buildings are 1,279,505 (detached building), 898,429 (collective building), and 560,423 (industrial \& commercial building).

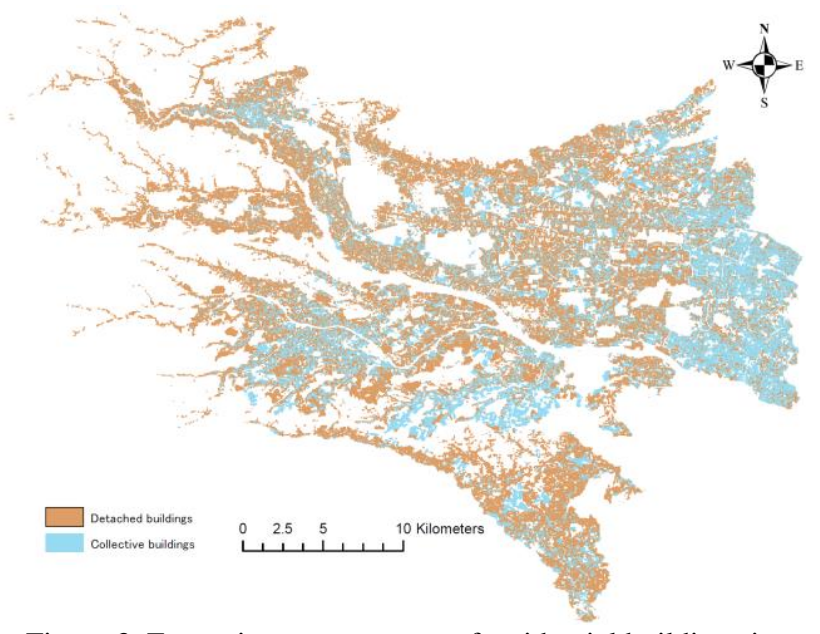

Figure 3. Extraction on two types of residential buildings in Tokyo (raster map at a resolution of $50 \times 50 \mathrm{~m}$ ): blue-collective buildings, orange-detached buildings

To estimate the height of building, a remote sensing-based DSM and DEM raster maps are used. The DEM map at a resolution of $5 \times 5 \mathrm{~m}$ is made by airborne laser measurement (Geospatial Information Authority of Japan, 2016). The DSM map at a resolution of $30 \times 30 \mathrm{~m}$ is made by processing the satellite image taken by Advanced Land Observing Satellite (ALOS) and provided by Japan Aerospace Exploration Agency (Takaku et al., 2014). As the resolution of two maps are different, the DEM is resampled as $30 \times 30 \mathrm{~m}$ DEM raster. Then, the representative point of each building is generated from 
building polygon as a carrier to extract the values from $30 \times 30$ $\mathrm{m}$ DEM and DSM maps by using the extract multi values to points tool. And the DEM and DSM values of points are linked with each building polygon by using the add join tool. Through Calculate Field tool, the height of each building is estimated by subtracting DEM value from DSM value.

After height calculation, the mean floor height (MFH) is assumed through Calculate Field tool for all buildings $(2.9 \mathrm{~m}$ for residential buildings, and $3.3 \mathrm{~m}$ for industrial \& commercial buildings). And then floor numbers of each building are estimated by using the height divided by MFH. The site area of each building is calculated automatically by using the Geometry Operation tool. Moreover, the total floor area is calculated by using site area multiplied by the floor number through Calculate Field tool. All buildings are added with attributes on site area, type, height, floor number, and total floor area.

\section{3 $\mathrm{CO}_{2}$ emissions estimation from national census data}

The $\mathrm{CO}_{2}$ emissions from residential sector are estimated by using detailed family numbers from the population census data (2015 population census) and that from industrial \& commercial sector are estimated by using detailed labor numbers from the economic census data (2014 economic census). As lack of information at the building level regarding what kind of fuel is used in which building, we assume a uniform fuel use of natural gas, liquefied petroleum gas and kerosene in each family. And the nonelectric emissions factors of that are derived from investigation report and official publication. In Japan, the national census data are mapped by census area level, therefore, additional allocation efforts should be made to achieve the visualization on emissions by building level.

For residential sector, the emissions are estimated directly from energy consumption by all families in each census area. The population census contains family numbers for 6 types of family composition and building number for 2 types of building in 5,578 census areas. Combing with the annual nonelectric carbon intensity data by family composition type and type of building that derived from an investigation report (Mitsubishi Research Institute, Inc., 2016), the emissions from families by types of buildings are estimated for each census area. The $\mathrm{CO}_{2}$ emissions estimated basing on population census are mapped at census area level as shown in figure 4 . The areas in red reflect higher annual emissions and that in green show lower emissions from residential sector.

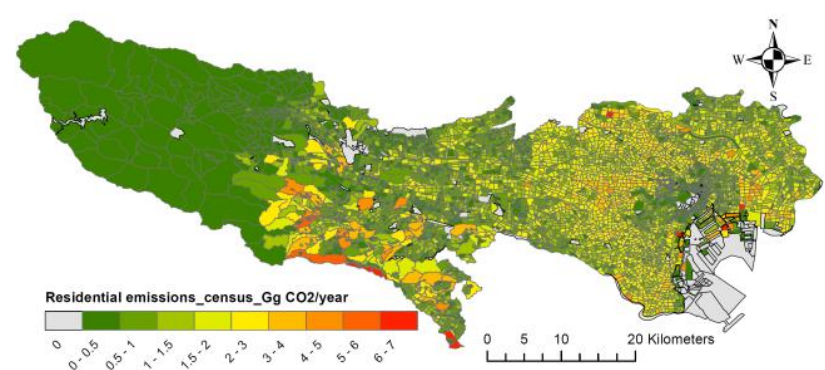

Figure 4. $\mathrm{CO}_{2}$ emissions from residential sector estimated from population census, unit: $\mathrm{Gg} \mathrm{CO}_{2} \mathrm{yr}^{-1}$

For industrial and commercial sector, familiar with the residential sector the emissions are firstly estimated by using the labor numbers for 18 industry types from national economic census multiplied by the annual nonelectric carbon intensity data for each type of industry. The economic census contains labor numbers for each type of industry in 5,318 census areas. The emission factors per labor by industry types are derived from energy balance table for Tokyo reported by government statistics (Agency for Natural Resources and Energy, 2017). The $\mathrm{CO}_{2}$ emissions estimated from economic census are mapped by census area level as shown in figure 5 . The areas in red reflect higher annual emissions and that in green show lower emissions from industrial \& commercial sector.

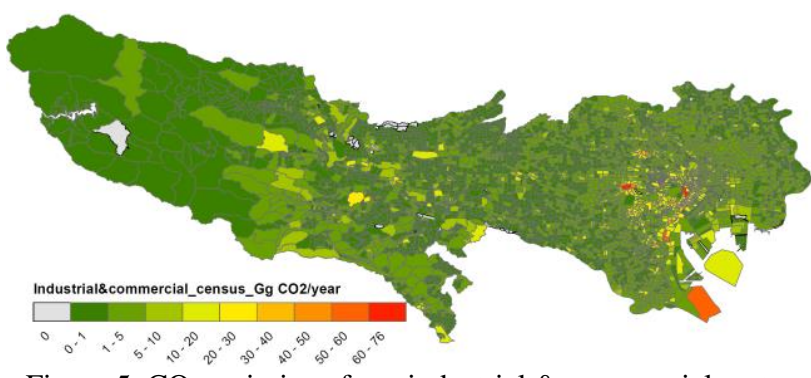

Figure 5. $\mathrm{CO}_{2}$ emissions from industrial \& commercial sector estimated from economic census, unit: $\mathrm{Gg} \mathrm{CO}_{2} \mathrm{yr}^{-1}$

\section{$2.4 \mathrm{CO}_{2}$ emissions allocation for each building}

To allocate the annual emissions for each building, the total floor area of buildings in each census area and the emissions capita by area are summarized. For that, Spatial Join and Summary tools is applied to summarize total floor area of all buildings in each census area. And then the emissions capita by area are estimated through Calculate Field tool. Then, total floor area of each building is multiplied by the emissions capita by area to calculate the emissions of each building.

There are 2,177,934 buildings are allocated by the residential emissions and 560,423 buildings are allocated by the industrial $\&$ commercial emissions. The partly extracted of the industrial \& commercial building emissions map by building level is shown as 3 dimensional in figure 6 . The buildings in red reflect higher emissions and greens show lower ones.

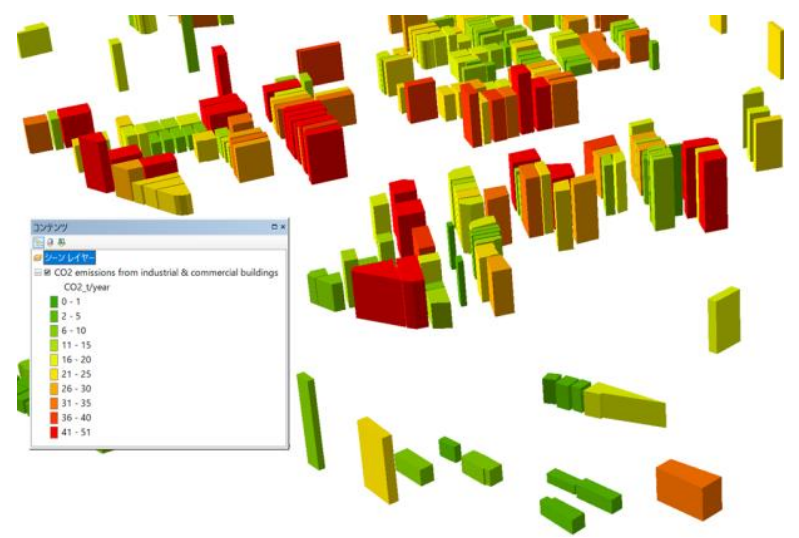

Figure 6. extraction of the industrial \&commercial emissions by building level shown by 3 dimensional

\section{RESULTS AND DISCUSSIONS}

\subsection{Estimation result}

After $\mathrm{CO}_{2}$ emissions from all buildings are estimated, the visualization tool of Symbol is used to show the building emissions on map. As the volume of buildings polygon map is very large, an empty mesh at a resolution of $1 \times 1 \mathrm{~km}$ (about 30 
$\times 30$ Seconds) is generated by using Grid Index Features tool to summarize the total emissions in each grid by using the Spatial Join and Summary tools. As the residential emissions map shown in figure 7, in eastern Tokyo the grids in red show higher emissions from building and in western area the grids in green show lower building emissions. Compared with the figure 4, we found significant change of emissions distribution occurred as the re-summarization. The reason is that after the allocation the distribution of emissions by grids are determined by the total area of buildings in a census area.

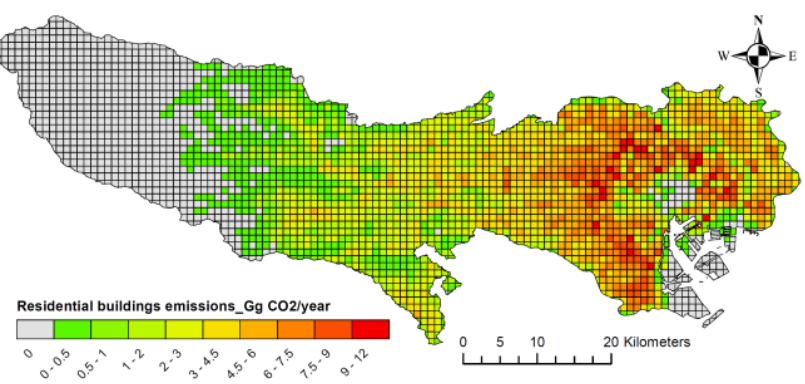

Figure 7. $\mathrm{CO}_{2}$ maps on emissions from residential buildings of Tokyo in 2014, unit: $\mathrm{Gg} \mathrm{CO}_{2}$ grid $^{-1} \mathrm{yr}^{-1}$

As shown in figure 8 , the industrial \& commercial building emissions show a different distribution with residential building emissions. The red grids in the center of eastern Tokyo where the density of high floor commercial buildings is larger. The green grids show smaller emissions where industrial and commercial buildings are less.

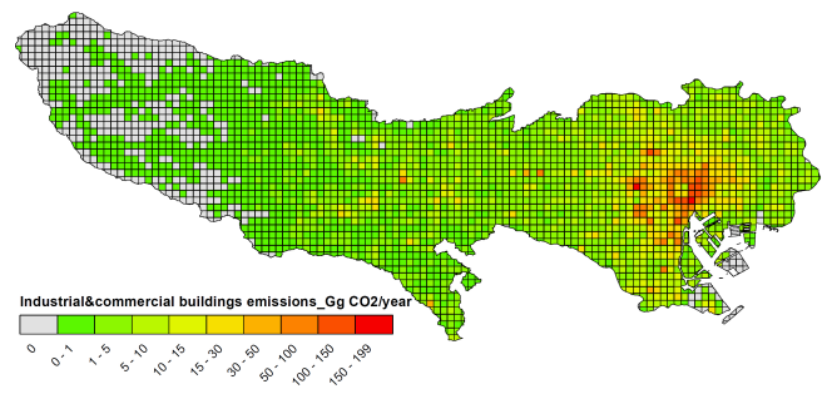

Figure 8. $\mathrm{CO}_{2}$ maps on emissions from industrial \& commercial buildings of Tokyo in 2014, unit: $\mathrm{Gg} \mathrm{CO}_{2}$ grid $^{-1} \mathrm{yr}^{-1}$

\begin{tabular}{|c|c|c|c|c|}
\hline \multirow[b]{2}{*}{ Items } & \multicolumn{2}{|c|}{ Population census } & \multicolumn{2}{|c|}{ Economic census } \\
\hline & $\begin{array}{l}\mathrm{Min} . \\
\mathrm{CO}_{2}\end{array}$ & $\begin{array}{l}\mathrm{Max} . \\
\mathrm{CO}_{2}\end{array}$ & $\begin{array}{l}\text { Min. } \\
\mathrm{CO}_{2}\end{array}$ & Max. $\mathrm{CO}_{2}$ \\
\hline $\begin{array}{l}\text { Emissions: } \\
\text { tonne } \mathrm{CO}_{2} \mathrm{yr}^{-1}\end{array}$ & 3.6 & 6,924 & 1.1 & 82,244 \\
\hline $\begin{array}{l}\text { Family/labor } \\
\text { number }\end{array}$ & 4 & 7,998 & 1 & 73,672 \\
\hline $\begin{array}{l}\text { Capita by } \\
\text { family/labor } \\
\text { number: kg } \\
\mathrm{CO}_{2} / \text { person } \mathrm{yr}^{-1}\end{array}$ & 902 & 866 & 1,121 & 1,116 \\
\hline $\begin{array}{l}\text { Total floor area } \\
\text { of buildings in } \\
\text { census area }\left(\mathrm{m}^{2}\right)\end{array}$ & 3,353 & 529,738 & 1,695 & $1,084,123$ \\
\hline $\begin{array}{l}\text { Capita by total } \\
\text { floor area: } \mathrm{kg} \\
\mathrm{CO}_{2} / \mathrm{m}^{2} \mathrm{yr}^{-1}\end{array}$ & 1.1 & 13.1 & 0.7 & 70.1 \\
\hline
\end{tabular}

Table 1. Extraction of building emissions estimated by census area level
Focusing on the minimum and maximum emissions areas that estimated from two censuses, the relevant parameters are listed in Table 1. From Table1, the total annual emissions are from 3.6 to 6,924 tonne $\mathrm{CO}_{2} \mathrm{yr}^{-1}$ in population census area and that are from 1.1 to 82,244 tonne $\mathrm{CO}_{2} \mathrm{yr}^{-1}$ in economic census area. Carbon emissions capita by family/labor number decreases as the increasing number of that.

As a result, the emissions from two sectors by building type and the corresponding building number are summarized in the Table 2. As a result, 2,738,357 buildings of Tokyo in 2014 with annual total emissions of $18,861 \mathrm{Gg} \mathrm{CO}_{2}$. That from residential buildings of Tokyo in 2014 are about 5,826 $\mathrm{Gg} \mathrm{CO}_{2} \mathrm{yr}^{-1}$ and that from industrial \& commercial buildings of Tokyo in 2014 are about $13,035 \mathrm{Gg} \mathrm{CO}_{2} \mathrm{yr}^{-1}$.

\begin{tabular}{|l|c|c|c|}
\hline Sector & Type & $\begin{array}{c}\text { Building } \\
\text { number }\end{array}$ & $\begin{array}{c}\text { Emissions } \\
\mathrm{GgCO}_{2} \mathrm{yr}^{-}\end{array}$ \\
\hline Residential & $\begin{array}{c}\text { Detached } \\
\text { buildings } \\
\text { Collective } \\
\text { buildings }\end{array}$ & $1,279,505$ & 2,029 \\
$\begin{array}{l}\text { Industrial \& } \\
\text { commercial }\end{array}$ & $\begin{array}{c}\text { Industrial \& } \\
\text { commercial } \\
\text { buildings }\end{array}$ & 568,429 & 3,797 \\
Total & $2,738,357$ & 18,035 \\
\hline
\end{tabular}

Table 2. Estimation result for Tokyo in 2014 by sectors

\subsection{Discussion}

As described by (Zhou et al., 2010), Hesita approach estimated the emissions from residential buildings by using the total floor area of each building multiplied by nonelectric energy consumption capita that was estimated from an energy consumption simulation tool. Different with that approach, we used the national population census as activity data to estimate the residential emissions from fossil fuel consumed by families in relevant buildings for each census area and allocate them into each residential building. The annual nonelectric emissions are counted as family total using detailed census data and summarized for the building total emissions. The annual nonelectric carbon intensity data for 6 types of families are derived from an investigation report for energy used in residential sector. For commercial sector, the emissions are estimated by using the total floor area of each building multiplied by the nonelectric energy consumption capita by area in Hesita project. However, we estimated that by using the data on labor numbers of 18 types of industries in the economic census areas and allocated the emissions into each building. The annual carbon intensity data for per labor of each type of industry that are derived from energy balance table of Tokyo. The detailed carbon intensity data we used are extracted from existing survey report and energy statistics rather than the data estimated from energy simulation tool that could avoid system errors. The national census we used is comprise of data for each local community in Japan. Thus, it is possible to apply our method in any other city of Japan.

The limitations of the study are mainly referred to the uncertainty that contained in the emissions result and the mapping processes. According to the availability of spatial data, a better mapping technique especial on building types distinction should be explored. The high GIS technique is essential to achieve this kind of visualization. Moreover, if there is more detailed activity data on residential and industrial \& 
commercial sectors, the uncertainties from the allocation efforts could be decreased. We should make carefully error estimates. Considerable future step is like to implement temporary variation for two sectors from the seasonal, weekly, and diary aspects. And to compile the emissions for other sectors of Tokyo.

\section{CONCLUSIONS}

In this study, we developed a method on achieving the highresolution quantification of $\mathrm{CO}_{2}$ emissions from buildings of Tokyo in 2014. The total $\mathrm{CO}_{2}$ emissions from residential buildings of Tokyo in 2014 are about $5,826 \mathrm{Gg}$ and that from industrial \& commercial buildings are about 13,085 Gg. The method basing on bottom-up approach and supplemented with some allocation efforts could be applied in any other city of Japan. The visualization of that is achieved by linking the national census data with spatial data. And the highlight points of these efforts are emissions estimation basing on detailed census data and allocation of that for high-resolution map. As the success on mapping for the $\mathrm{CO}_{2}$ emissions from buildings in urban domain, it will support the local climate actions in future.

The specific size of gridded emission data product e.g. $1 \times 1 \mathrm{~km}$ by various types of formats (e.g. Shape, image, geotiff...) are available from the author.

\section{REFERENCES}

Agency for Natural Resources and Energy, 2017. Energy balance table of Tokyo, http://www.enecho.meti.go.jp/statistics/energy_consumption/ec 002/results.html\#headline2 (1 October2017).

Duren, R. M., and Miller, C. E., 2012. Measuring the carbon emissions of megacities. Nature Climate Change, 2(8), 560.

Feng, S., Lauvaux, T., Newman, S., Rao, P., Ahmadov, R., Deng, A., Díaz-Isaac, L. I., Duren, R. M., Fischer, M. L., Gerbig, C., Gurney, K. R., Huang, J., Jeong, S., Li, Z., Miller, C. E., O'Keeffe, D., Patarasuk, R., Sander, S. P., Song, Y., Wong, K. W., and Yung, Y. L., 2016. Los Angeles megacity: a highresolution land-atmosphere modelling system for urban $\mathrm{CO}_{2}$ emissions, Atmos. Chem. Phys., 16, pp. 9019-9045, https://doi.org/10.5194/acp-16-9019-2016.

Fukui, T., Kokuryo, K., Baba, T., Kannari, A., 2014. Updating EAGrid2000-Japan emissions inventory based on the recent emission trends (in Japanese). Journal of Japan Society for Atmospheric Environment, 49(2), pp. 117-125.

Geospatial Information Authority of Japan, 2016. DEM data download service,

https://fgd.gsi.go.jp/download/menu.php (1October2017).

Gurney, K. R., Razlivanov, I., Song, Y., Zhou, Y., Benes, B., and Abdul-Massih, M., 2012. Quantification of fossil fuel $\mathrm{CO}_{2}$ emissions on the building/street scale for a large US city. Environ. Sci. Technol., 46(21), pp. 12194-12202, http://doi.org/10.1021/es3011282.

Kannari, A., Tonooka, Y., Baba, T., and Murano, K., 2007. Development of multiple-species $1 \mathrm{~km} \times 1 \mathrm{~km}$ resolution hourly basis emissions inventory for Japan. Atmos. Environ., 41(16), pp. 3428-3439.
Mitsubishi Research Institute, Inc., 2016. Investigation on energy consumption in residential department (in Japanese), Report of Mitsubishi Research Institute, pp. 1-171.

Mori, Y., Machimura, T., Matsui, T., and Oda, T., 2015. Towards multi-scale mapping of human carbon dioxide emissions from megacity Osaka, Japan,17th Global Emission Initiative Conference Proceedings.

Patarasuk, P., Gurney, K.R., O'Keeffe, D., Song, Y., Huang, J., Rao, P., Buchert, M., Lin, J.C., Mendoza, D., and Ehleringer, j.R., 2016. Urban high-resolution fossil fuel $\mathrm{CO}_{2}$ emissions quantification and exploration of emission drivers for potential policy applications, Urban Ecosyst., https://doi.org/10.1007/s11252-016-0553-1.

Rayner, P. J., Raupach, M. R., Paget, M., Peylin, P., and Koffi, E., 2010. A new global gridded data set of $\mathrm{CO}_{2}$ emissions from fossil fuel combustion: Methodology and evaluation. $J$. Geophys. Res. Atmos., 115(D19).

Sanna, L., Ferrara, R., Zara, P. and Duce, P., 2014. GHG emissions inventory at urban scale: the Sassari case study, Energy Procedia, 59, pp. 344-350, https://doi.org/10.1016/j.egypro.2014.10.387.

Satterthwaite, D., 2008. Cities' contribution to global warming: notes on the allocation of greenhouse gas emissions. Environ. urban., 20(2), pp. 539-549.

Statistics Japan, 2016. 2014 Economic Census, http://www.stat.go.jp/english/index.htm (1October2017).

Statistics Japan, 2017. 2015 Population Census, http://www.stat.go.jp/english/index.htm (1October2017).

Takaku, J., Tadono, T., and Tsutsui K., 2014. Generation of High Resolution Global DSM from ALOS PRISM, The International Archives of the Photogrammetry, Remote Sensing and Spatial Information Sciences, Vol. XL-4, pp. 243-248.

Zhou, Y., and Gurney, K., 2010. A new methodology for quantifying on-site residential and commercial fossil fuel $\mathrm{CO}_{2}$ emissions at the building spatial scale and hourly time scale. Carbon Manag., 1(1), pp. 45-56. 